\title{
Enfermagem e atenção à saúde do trabalhador: a experiência da ação de imunização na Fiocruz/Manguinhos
}

\author{
Nursing and healthcare for workers: \\ the experience of the immunization action at Fiocruz/Manguinhos
}

Paula Raquel dos Santos ${ }^{1}$

Nathalia Henrique Noronha ${ }^{2}$

Ubirajara Aluizio de Oliveira Mattos ${ }^{3}$

Delson da Silva ${ }^{1}$

${ }^{1}$ Departamento de

Enfermagem em Saúde

Pública, Faculdade de

Enfermagem, Universidade

do Estado do Rio de Janeiro.

Boulevard 28 de setembro

$157,7^{\circ}$ andar, Vila Isabel.

20551-030 Rio de Janeiro

RJ.paula.raquel0@gmail.com

${ }^{2}$ Corpo de Bombeiros

Militar do Estado do Rio de

Janeiro.

${ }^{3}$ Departamento de

Engenharia Sanitária e Meio

Ambiente, Faculdade de

Engenharia, Universidade do

Estado do Rio de Janeiro.
Abstract The worker, while doing his activities in contact with patogenic agents, is exposed to the risk of getting diseases that could result in death. The immunizaton appears as one of the ways to preserve and protect against this contamination. This article presents an experience of workers immunization during the period of 2005 to 2008, by the implantation of the project Nursing Integral Actions of Worker's Health Vigilance at Fundação Oswaldo Cruz (Fiocruz), Manguinhos campus, Rio de Janeiro. This is a descriptive, explorative and quantitative study, using primary data from the construction of the project. During the project 12.904 doses of different vaccines were applied in a population with a variety of job activities and ages. Civil construction, security, gardenering, maintenence and clearing service teams were the most mobilized and receptive to the activities. With this experience it was possible the instalation of the vaccination room at CST/DIREH/Fiocruz, the implantation of campaigns at the unities, specific immunization actions to the workers and operative groups and lectures focused in health education. Key words Occupational immunization, Worker's health surveillance, Human resources and work, Environment and health
Resumo O trabalhador, ao realizar atividades em que exista o contato com agentes patogênicos, se expõe ao risco de adquirir doenças que podem levá-lo à morte. A imunização aparece como uma das medidas de prevenção e proteção contra o seu adoecimento. Este artigo apresenta a experiência de imunização em trabalhadores, no período de 2005 a 2008, através da implantação do projeto Ações Integradas de Enfermagem em Vigilância da Saúde do Trabalhador na Fundação Oswaldo Cruz, campus Manguinhos, Rio de Janeiro (Fiocruz/Manguinhos). Trata-se de um estudo descritivo exploratório quantitativo, utilizando dados primários resultantes da construção do projeto de trabalho na linha temática da vigilância em saúde do trabalhador. Nesse período, aplicaramse 12.904 doses de vacinas variadas em uma população de trabalhadores de atividades e faixas etárias diversificadas. Construção civil, segurança, jardinagem, manutenção e serviço de limpeza foram aquelas com maior mobilização e receptividade dos trabalhadores. A experiência possibilitou a instalação da sala de vacina no CST/DI$R E H$, realização de campanhas nas unidades, realização de ações de imunização específicas para trabalhadores e de grupos operativos e palestras voltadas à educação em saúde.

Palavras-chave Imunização ocupacional, Vigilância em saúde do trabalhador, Recursos humanos e trabalho, Meio ambiente e saúde 


\section{Introdução}

Apresentamos o tema imunização na perspectiva da saúde coletiva, com enfoque na saúde do trabalhador, através das dimensões humanas no trabalho e das diferentes estratégias adotadas para estudo e intervenção com metodologias na relação saúde-trabalho ${ }^{1}$. Apontamos metodologias de investigação, avaliação e intervenção para prevenção, detecção e proteção à saúde dos trabalhadores diante dos fatores de risco com potencial de contaminação por bioagentes presentes nos diferentes processos de trabalho e geradores de agravos e doenças ocupacionais transmissíveis aos trabalhadores.

As doenças de notificação compulsória e as imunopreveníveis, as taxas de incidência e de prevalência, a mortalidade e o grau de letalidade de determinada doença representam a magnitude e a necessidade de desenvolver recursos e tecnologias para a formulação de uma vacina, bem como definir a sua disponibilidade para as coletividades e para as ações de promoção da saúde ${ }^{2}$.

O Programa Nacional de Imunizações (PNI) foi instituído no Brasil em 1973 com a finalidade de garantir a imunização para toda a população brasileira, através dos municípios e serviços de saúde da rede básica. Inicialmente, atendeu às necessidades emergenciais do programa de controle da tuberculose e da erradicação da varíola. A Lei $\mathrm{n}^{\circ} 6.259 / 75$ institucionalizou o programa e definiu as competências e responsabilidades relacionadas à sua aplicação ${ }^{3}$.

As vacinas são administradas em função do calendário de imunização instituído pelo PNI, de responsabilidade da Fundação Nacional de Saúde (Funasa) e do Centro Nacional de Epidemiologia (Cenepi). Possui logística de atenção focada e direcionada para grupos humanos e populacionais da coletividade. Por exemplo: a imunização de grupos indígenas, a imunização do adulto, o calendário infantil e a imunização do idoso ${ }^{4}$.

Imunizar o trabalhador como forma de evitar que este venha a adoecer quando em contato com agentes patogênicos inerentes aos riscos biológicos dos processos produtivos em organizações de saúde foi a questão que norteou a reflexão sobre o tema. Neste campo de conhecimento, o levantamento dos modos operacionais pela análise da atividade e da gestão dos processos de trabalho, o conhecimento do planejamento central do sistema de saúde em vigor em dado território e a gestão dos serviços de saúde e da rede de organização do cuidado permitem a sistematização das ações abrangentes em imunização nos diferentes espaços de trabalho.
Situaremos as proposições e os aspectos referentes ao tema a partir da experiência de construção do programa de imunização de forma institucional durante a implementação do projeto intitulado Ações Integradas de Enfermagem em Vigilância da Saúde do Trabalhador, vinculado ao programa Fiocruz Saudável, implantado em 2005 na Fundação Oswaldo Cruz (Fiocruz) no campus Manguinhos/Rio de Janeiro ${ }^{5}$. Desse modo, objetivamos explanar a experiência de implantação da imunização de trabalhadores e apresentar uma metodologia integrada desta ação pela análise dos resultados da implantação.

Um dos grandes avanços acerca das medidas de prevenção e promoção em saúde tem sido o romper dos elos da cadeia de transmissão das doenças, através da administração de imunobiológicos. A imunização do trabalhador aparece como ação preventiva com contribuições para preservação da sua saúde ${ }^{6}$. Os benefícios se estendem à redução da ocorrência de absenteísmo por adoecimento, manutenção da produtividade no trabalho e proteção da coletividade ${ }^{7}$.

A ação de imunização em saúde do trabalhador, devido às suas especificidades, tem como características a interdisciplinaridade e a multiprofissionalidade ${ }^{8}$. Dessa forma, requer o uso de metodologias integradas a fim de contemplar os diversos aspectos que a questão evidencia. Este artigo, que apresenta a aplicabilidade desta integração metodológica, poderá contribuir como referência para futuras experiências de elaboração de programas de imunização de trabalhadores em organizações públicas e privadas.

$\mathrm{Na}$ técnica de avaliação em saúde, a imunização é uma ação que precede os exames ocupacionais, sendo uma intervenção específica para os fatores de risco biológico imunopreveníveis. Esta ação está implícita na Portaria no 3.214 do Ministério do Trabalho e Emprego (MTE) como atribuição do Serviço Especializado de Segurança e Medicina do Trabalho (SESMT/NR-4) e também no modelo de saúde do trabalhador de vigilância em saúde para as empresas públicas, privadas, estabelecimentos e serviços de saúde e laborató$\operatorname{rios}^{9-11}$. A legislação brasileira e as câmaras técnicas das associações dos profissionais que compõem os SESMT definem que a imunização é uma atividade de prevenção e promoção da saúde dos trabalhadores.

A história vacinal de cada trabalhador define as vacinas que ainda deverão ser administradas, bem como a implementação de vacinas relacionadas à exposição ocupacional. Assim, promove-se, de forma eficaz e eficiente, a ruptura da 
cadeia de transmissão de doenças imunopreveníveis no ambiente de trabalho ${ }^{6}$.

A biossegurança tem contribuído nas barreiras de proteção individual por incluir a imunização como uma intervenção aplicada aos processos de trabalho - dentre outros, em serviços e laboratórios de saúde. Ela se tornou instrumento de prevenção em saúde dos trabalhadores envolvidos em processos produtivos que manipulam agentes biológicos, bem como em promoção da saúde, o que significa ir além dos riscos ocupacionais devido ao contingente de indivíduos envolvidos indiretamente nos processos produtivos ${ }^{12}$.

Vivemos em meios coletivos, e as ações de prevenção de riscos derivados de uma atividade específica podem afetar a comunidade do entorno, além do colega que labuta ao seu lado, do técnico que o auxilia e de outras pessoas que participam direta ou indiretamente desta atividade (p. 2) ${ }^{12}$.

A compreensão ambiental para o campo da saúde do trabalhador suscita, no caso específico do estudo aplicado, intervenção sobre a proposta acerca dos ambientes saudáveis e com qualidade. Neste aspecto, uma área restrita e/ou ambiente de trabalho demandam a investigação do ecótopo contaminado, a entrada do bioagente patogênico e o indivíduo exposto e suscetível que é componente ativo e indissociável do seu ecossistema ${ }^{6}$.

As necessidades de medidas preventivas nos estabelecimentos de serviços de saúde para doenças profissionais de relevância, como a tuberculose e a hepatite B em seu modo de transmissão ocupacional, é ressaltada pela relação saúdetrabalho e redução de agravos e doenças ligadas ao processo de adoecimento no trabalho. Outra questão importante diz respeito à ocorrência de acidentes de trabalho com objeto perfurocortante, cuja subnotificação no Brasil não afasta a necessidade de intervenção sobre o número crescente de casos em serviços de saúde. Desse modo, a imunização do trabalhador aparece como aliada na prevenção de doenças transmissíveis nos diversos locais e atividades de trabalho ${ }^{13}$.

\section{Metodologia}

Este artigo é resultante de estudo descritivo exploratório quantitativo utilizando dados primários resultantes da construção do projeto de trabalho na linha da vigilância em saúde do trabalhador, pelos moldes dos programas de saúde do Ministério da Saúde para a atenção básica, com especificidade para o trabalhador na instituição Fiocruz/Manguinhos.
O campus Manguinhos está localizado na Avenida Brasil, em uma área de 800.000 metros quadrados, onde se situam oito unidades que desempenham ações de ensino, pesquisa e serviços. Na produção de insumos à saúde, destacase o Instituto de Tecnologia em Imunobiológicos (Bio-Mangunhos), maior centro produtor de vacinas e kits de reagentes para o diagnóstico de doenças infectocontagiosas da América Latina ${ }^{14}$.

Estabelecemos metodologias de investigação, avaliação e intervenção, sistematizadas pelos conhecimentos da segurança no trabalho, imunologia, microbiologia, saúde pública, planejamento e gestão de serviços e cuidados em saúde, imunização, enfermagem, vigilância em saúde, educação em saúde e meio ambiente.

Em sua fase exploratória, utilizamos a revisão bibliográfica sobre o tema com os descritores imunização em saúde do trabalhador e imunização ocupacional, bem como o estudo do material técnico-científico do Mistério da Saúde e da Sociedade Brasileira de Pediatria e de Imunização - o mapeamento de risco, o levantamento de riscos biológicos e de acidentes, além da análise dos registros descritivos de acidentes de trabalho e das visitas técnicas a ambientes de trabalho que embasam a apresentação das informações.

Pelo método aplicado de vigilância à saúde do trabalhador, foi realizada análise dos relatórios do serviço de enfermagem do Núcleo de Saúde do Trabalhador (NUST), inserido na Coordenação de Saúde do Trabalhador (CST) vinculada à Diretoria de Recursos Humanos (DIREH), entre os anos de 2005 e 2008, e dos seguintes registros: imunobiológicos aplicados enviados à Secretaria Municipal de Saúde do Rio de Janeiro (SMS/RJ), campanhas de vacinação realizadas na instituição, notificações de reações adversas enviadas à Secretaria de Estado de Saúde do Rio de Janeiro (SES/RJ), consolidados das notificações dos acidentes de trabalho e do perfil do trabalhador da Fiocruz pela equipe de enfermagem atuante no projeto.

No período descrito, o programa de imunização abrangeu, em razão do processo e da organização do trabalho, as seguintes unidades do campus Manguinhos: unidades laboratoriais Instituto Oswaldo Cruz (IOC), Instituto Nacional de Controle de Qualidade em Saúde (INCQS), Escola Nacional de Saúde Pública Sergio Arouca (Ensp) e Centro de Criação de Animais de Laboratório (Cecal); unidades de produção industrial - Bio-Manguinhos e Farmanguinhos; serviços de saúde - Instituto de Pesquisa Evandro Chagas (Ipec), Centro de Saúde Escola Germano Sin- 
val Farias (CSEGSF/Ensp); ambientes fechados e escritórios - Centro de Informação e Tecnologia (CICT), Diretoria de Recursos Humanos (DI$\mathrm{REH}$ ), Diretoria Administrativa do Campus (DIRAC), Diretoria Administrativa de Desenvolvimento (DIRAD), Casa de Oswaldo Cruz (COC), Escola Politécnica, Presidência e áreas de administração ${ }^{14}$.

A ação de imunização contou com uma equipe de trabalho composta por profissionais de saúde treinados e capacitados para o processo de trabalho de imunização em serviços de saúde. A partir dos eixos de ação focados no ensino e pesquisa, administração, vacinação, notificação e vigilância, informação e educação em saúde, a equipe constitui-se de enfermeira do trabalho, acadêmicos de enfermagem da Faculdade de Enfermagem da Universidade do Estado do Rio de Janeiro (Uerj), estagiários do curso técnico de enfermagem do trabalho da Fundação de Apoio à Escola Técnica do Estado do Rio de Janeiro (Faetec), todos com vínculo de bolsista Centro de Integração Empresa-Escola (CIEE), técnicos em enfermagem do trabalho, médicos do trabalho, além do corpo administrativo da CST/DIREH.

\section{Resultados e discussão}

Inicialmente, a implementação de ações de imunização aplicadas à saúde do trabalhador desenvolveu-se com o projeto de trabalho institucional Ações Integradas de Enfermagem em Vigilância da Saúde do Trabalhador da Fiocruz, com recursos e financiamento do Sistema Único de Saúde (SUS) e com parceria e convênio de apoio técnico-educacional do projeto de extensão universitária Vacinando, da Faculdade de Enfermagem da Universidade do Estado do Rio de Janeiro ${ }^{15}$.

As ações do projeto se davam nos moldes de rotina de serviço junto aos acidentes de trabalho, promoção da saúde coletiva e exames admissionais e periódicos, cujas especificações foram apresentadas pela primeira autora deste artigo, enfermeira com vínculo institucional no período de 2005 a 2008, juntamente com o coordenador do projeto. Nortearam-se pelas áreas de conhecimento da saúde pública, saúde do trabalhador e da enfermagem do trabalho, estando vinculado ao organograma do gerenciamento do projeto Fiocruz Saudável, no eixo vigilância, e à CST/DIREH ${ }^{5}$.

Foi estabelecida parceria de cooperação técnica e de serviço com o Centro de Saúde Escola Germano Sinval Farias (CSEGSF) para a implantação da sala de imunização junto à CST, a epi- demiologia da SES/RJ e a gerência de imunização da SMS/RJ via divisão político-administrativa para a Área Programática (AP) 3.1 da VIII Região Administrativa (RA). Assim, propiciou-se o acesso dos trabalhadores, estudantes e bolsistas da instituição Fiocruz, com atendimento ao campus Manguinhos e em conformidade com as normas técnicas para imunização em serviços de saúde pelo SUS.

O projeto estruturou-se a partir da educação continuada em serviço interno e na rede básica do SUS, treinamento e capacitação da equipe de profissionais de saúde executores e níveis de responsabilização técnica pelo médico coordenador e pela enfermeira sanitarista e do trabalho. $\mathrm{O}$ acesso às ações de imunização se estabeleceu de forma direta com os trabalhadores representantes dos recursos humanos e gestão do trabalho das unidades que compõem o campus Manguinhos e dos responsáveis pelas categorias funcionais específicas de trabalhadores das empresas terceirizadas da construção civil, segurança e patrimônio, limpeza, jardinagem e manutenção.

A etapa inicial de trabalho foi a de conhecer os trabalhadores e as demandas das unidades com relação ao fator de risco biológico, o que direcionou a identificação dos grupos de trabalhadores e das especificidades dos processos de trabalho com avaliação do grau de aceitabilidade da ação proposta pelos trabalhadores. Encontrou-se mobilização e receptividade nas atividades vinculadas à construção civil, segurança, jardinagem, manutenção e serviço de limpeza, seguindo-se os técnicos de laboratório, administrativos e serviço de gestão, profissionais de saúde, profissionais de creche, trabalhadores da planta física de produção de imunobiológicos e de fármacos, graduandos e pós-graduandos, estagiários e bolsistas em pesquisa e pesquisadores chefes de unidades.

Através do instrumento administrativo do processo de trabalho em enfermagem do trabalho, denominado "movimentação diária de enfermagem", foram construídos os registros de identificação dos trabalhadores da Fiocruz/Manguinhos atendidos no NUST, permitindo-nos traçar o perfil da clientela de usuários. Ao longo do período estudado, revelaram-se as seguintes características dos trabalhadores: em sua maioria terceirizados, bolsistas e estudantes, na faixa etária entre 15 e 70 anos de idade, com discreto crescimento do número de servidores usuários e relativa procura destes para situações clínicas de hipertensão arterial sistêmica (HAS), queixas cardiovasculares e situações típicas de estresse em ambiente de trabalho ${ }^{16-18}$. 
Para a construção dos dados primários dos acidentes de trabalho, o formulário de notificação e o livro de registro, no item descrição do acidente, com relato da equipe de saúde, permitiram as referências de dados para a exposição aos fatores de risco biológico em processos de trabalho e em acidentes de trabalho perfurocortantes. Desse modo, priorizaram-se as especificidades das atividades de trabalho que requerem imunobiológicos específicos para situações de exposição e de acidente de trabalho com material biológico com potencial contaminante por bioagentes patogênicos ${ }^{16-18}$.

Segundo informativo NIST (Núcleo de Informação em Saúde do Trabalhador) de 2007, com dados das fontes NUST, NUST-IFF, equipe de engenharia e segurança do trabalho de Bio-Manguinhos, os acidentes de trabalho na Fiocruz foram cerca de 3,5 vezes maior do que o registrado na Previdência Social brasileira. Foram 422 acidentes em um ano, em uma população de trabalhadores de cerca de 10.000, resultando em uma taxa de incidência anual de 4.220/100.00 trabalhadores. Esta magnitude registrada deve-se à maior sensibilidade do Sistema Integral de Saúde do Trabalhador (SIST/Fiocruz), pois são informados também casos leves, transformando-o em registro adequado para análise epidemiológica dos acidentes por trazer informações consistentes que serviram de fundamento para o planejamento de intervenções diretivas em imunização ocupacional ${ }^{14}$.

Esse tipo de agravo é um dos mais tradicionais marcadores de situações de risco e consequentemente de focos de problemas a serem eliminados por ações específicas de prevenção voltadas ao ambiente de trabalho. Os acidentes de trabalho na Fiocruz são eventos heterogêneos que podem ocorrer em diferentes momentos do processo de trabalho; seu registro permite refletir em hipóteses causais de associação entre os riscos e a ocorrência de acidentes, para assim planejar e avaliar as medidas adotadas ${ }^{14}$.

Outra técnica metodológica empregada foi a construção de mapas de risco dos ambientes e processos de trabalho pelo coletivo dos trabalhadores. Esta metodologia permitiu a identificação de fatores de risco existentes nas atividades que compõem os processos de trabalho, além da interlocução com os trabalhadores e envolvimento em grupos de discussão para a formulação de reflexões e mudanças nos ambientes de trabalho. A experiência aplicada e específica foi primeiramente desenvolvida na unidade Ipec.

... a construção do mapa também pode, de fato, induzir no trabalhador uma perspectiva mais crí- tica e vigilante, como propõe a vigilância em saúde do trabalhador, ou aumentar a consciência de risco, melhorando a efetividade das ações de biossegurança. Em nosso entendimento, o mapa de risco possibilitou o replanejamento do processo de trabalho a partir da experiência cotidiana e coletiva vivenciada no decurso de sua elaboração e permitiu aos trabalhadores proporem soluções criativas para os problemas detectados ${ }^{19}$.

$O$ mais relevante foi a reflexão suscitada nos trabalhadores e a mudança de perspectiva de passivos e reclamantes para atores com capacidade de interferir sobre o ambiente de trabalho. Estas reflexões geraram "insights" sobre a natureza do trabalho executado, tensões, insatisfações e angústias que corresponderiam a simbolos sem cor, invisíveis aos olhos na linguagem do mapa, mas reconhecidamente essenciais para todos os envolvidos neste percurso. O desafio será sustentar ao longo do tempo, diante da realidade das relações de trabalho no mundo atual, o aprendizado trazido pelo mapa ${ }^{19}$.

Foram identificados postos de trabalho dos laboratórios das diferentes unidades, locais de manipulação e tratamento com animais de laboratório, bem como a construção civil, com indicativos para investigação de contaminação ocupacional, que contribuíram para o foco em imunobiológicos específicos e para o direcionamento de campanhas nos ambientes de trabalho ${ }^{16-18}$.

A estrutura de funcionamento da ação de imunização foi construída por meio de oficinas de discussão técnica com os profissionais do serviço de epidemiologia do Ipec, organização de eventos técnicos e científicos nas unidades com a participação da gerente de imunização da SMS/RJ e profissionais especialistas do Centro de Estudos da unidade INCQS. Além disso, investiu-se na orientação dos trabalhadores, público-alvo da ação, sobre o tema imunização nas unidades, tendo a abertura oficial do Programa de Imunização para a Saúde do Trabalhador da Fiocruz ${ }^{16-18}$ no Ipec com representantes das unidades: INCQS, CSGSF/Ensp, DIRAC e Farmanguinhos, com posterior expansão da abordagem para as unidades Farmanguinhos-Jacarepaguá e IFF, que contaram com a adesão dos servidores e dos trabalhadores terceirizados, bem como a inserção junto à avaliação de saúde do NUST, favorecendo a emissão do Atestado de Saúde Ocupacional (ASO) de forma sistemática e de rotina.

Quanto às ações educativas em saúde (pequenos grupos), desenvolveu-se a técnica de sala de espera em imunização agendada, palestras expositivas interativas com problematização sobre temas em saúde e trabalho referente aos pro- 
gramas implementados, curso de capacitação em mapa de risco, consulta de enfermagem pelo enfermeiro aplicada aos programas e ações específicos da equipe de enfermagem para orientação em imunização ${ }^{16-18}$. As normas de aplicação e de atendimento foram estabelecidas em conformidade com o PNI, com a aplicação do calendário de imunização do adulto e do idoso, em função do recorte do público-alvo e da idade laboral da população de trabalhadores ${ }^{20}$.

A execução de campanhas piloto nas unidades IOC, Ipec e INCQS foi a segunda estratégia de intervenção e avaliação. Elaborou-se também caderneta de imunização institucional com a expedição de 2.000 unidades entre os trabalhadores, com posterior substituição pela caderneta de imunização do SUS, além do recebimento dos demais impressos fornecidos juntamente com os insumos e recursos disponibilizados para a rede básica de atenção ${ }^{21}$.

A logística funcional estabeleceu-se pela interlocução e parceria com os representantes de recursos humanos das unidades da instituição através da orientação de organização dos trabalhadores por meio de listagem de identificação prévia com informações técnicas em saúde: identificação pessoal (idade, sexo, endereço completo e telefone para contato), identificação funcional (local e posto de trabalho, cargo e função), vínculo empregatício (nome da empresa e contrato de trabalho), histórico vacinal (carteira e comprovantes de vacinação anteriores, ressalvo médico). Assim, viabilizou-se o planejamento de previsão e provisão das ações técnicas em saúde e implementação do ato vacinal e das atividades de vigilância em saúde que compreendem todo o processo de imunização.

Após a identificação, visitas técnicas aos ambientes de trabalho, coleta de informação dos riscos das unidades, mapa de risco, análise dos registros de acidentes de trabalho, seguiu-se a análise técnico-científica e administrativa em saúde da demanda organizada para a concretização do público-alvo e das possibilidades e modos de comunicação e mobilização dos trabalhadores.

Esse momento de intervenção foi dividido em duas etapas. A primeira consistiu em educação em saúde, com a organização de grupos operativos e de reflexão expositiva com o aplicativo de dinâmicas de grupo no formato de perguntas e respostas temáticas sobre imunização e o processo vacinal com os trabalhadores alvos da ação ${ }^{22}$. Na segunda etapa, aplicaram-se as modalidades definitivas de intervenção dos tipos: campanhas, sala de imunização, minipostos de vacinação em ambientes de trabalho, triagem, história vacinal e prescrição de vacina, ato vacinal e orientações em imunização ${ }^{21}$.

O registro dos dados, a sistematização da informação e a construção do fluxo de atendimento partiram da compilação dos dados e da avaliação da cobertura vacinal da instituição, necessária ao avanço das ações no calendário do adulto e do idoso ${ }^{4}$ para a imunização ocupacional. Isto demandou o uso de sistema de informação em vigilância da saúde do trabalhador local. No nível central do SUS, cumpriram-se as definições de encaminhamento para o Serviço de Vigilância em Saúde e Epidemiologia da SES/RJ dos registros de notificação de reações adversas com posterior recebimento do cuidado a ser prestado ao trabalhador, cuja análise epidemiológica definia a necessidade de cuidados especiais ${ }^{23}$.

As questões administrativas envolveram instâncias do planejamento e gestão do cuidado em rede de serviços de saúde do SUS. O replanejamento do trabalho foi um processo de construção contínuo ${ }^{24}$ devido às múltiplas interlocuções que envolvem a lógica de mudança de paradigma em imunização proposta por meio de fluxos ${ }^{25}$ de ação e modos de comunicação estabelecidos pelos fluxogramas gerados desta experiência.

No ano de 2005, a campanha de imunização em ambiente de trabalho totalizou a administração de 1.700 doses das vacinas dupla adulto, influenza e tríplice viral. Realizou-se também, com a participação dos graduandos e professores do internato da FENF/Uerj, a análise da história vacinal e levantamento da demanda para imunização prevista para o adulto, totalizando 2.400 atendimentos $^{16-18}$.

O desenvolvimento da metodologia de vigilância epidemiológica em saúde do trabalhador teve seu aprimoramento no ano de 2006, com a implementação dos seguintes registros oficiais definidos pelo PNI, Sistema de Informação de Agravos de Notificação (Sinan), SIST e do serviço de enfermagem/NUST: notificação de reações adversas; orientações para imunização do adulto e do trabalhador; rotina do calendário de imunização do adulto; campanhas de imunização com adesão à rede municipal de saúde; imunização ocupacional (ações específicas); registros de estatística de sala de vacina; registro em estatística diária de enfermagem; registro em caderneta de imunização; registro em espelho de sala de vacina; registro em sistema de informação ${ }^{16-18}$.

A implementação do projeto em 2006 totalizou a administração de 1.816 doses de vacina dupla adulto (dT), 1.683 doses da vacina anti- 
hepatite B, 309 doses de anti-influenza, 275 doses de tríplice viral, 33 doses de antifebre amarela e três doses de anti-hepatite $\mathrm{A}$, com a realização de 12 campanhas de imunização nas unidades da Fiocruz/Manguinhos, seguidas das doses subsequentes do esquema vacinal para hepatite b e dT.

Em 2007, a imunização em sala de vacina no NUST dos trabalhadores do campus Manguinhos contabilizou a administração de 1.072 doses de dupla adulto (dT), 1.302 doses de antihepatite B, 1.601 doses de anti-influenza, 738 doses de tríplice viral, 95 doses de antifebre amarela, três doses de anti-hepatite A e sete doses antivaricela. Foram realizadas ainda três campanhas de vacinação no NUST, uma no Ipec e uma em Farmanguinhos.

Em 2008, a imunização dos trabalhadores do campus Manguinhos realizada em sala de vacina contabilizou 2.267 doses de imunobiológicos administrados. Ressaltamos que no primeiro semestre de 2008 a vacina dupla adulto (dT) teve apenas 419 doses aplicadas, devido à falta deste imunobiológico na rede SUS. A vacina contra a hepatite B foi de 485 doses, a vacina influenza com 1.084 doses, a vacina antifebre amarela com 119 doses, a vacina tríplice viral com 122 doses, a vacina contra hepatite A com 19 doses e a vacina antirrábica com 19 doses.

Os dados de administração de imunobiológicos foram sistematizados em gráficos apresentados nos gráficos 1 e 2. O Gráfico 1 demonstra um decréscimo no fornecimento de doses de $\mathrm{dT}$ e hepatite B a serem administradas e do não retorno dos trabalhadores para as doses subsequentes do esquema vacinal. A demanda por vacinação contra febre amarela teve aumento devido à expansão de atividades nos campi avançados da Fiocruz com aumento do número de tra-

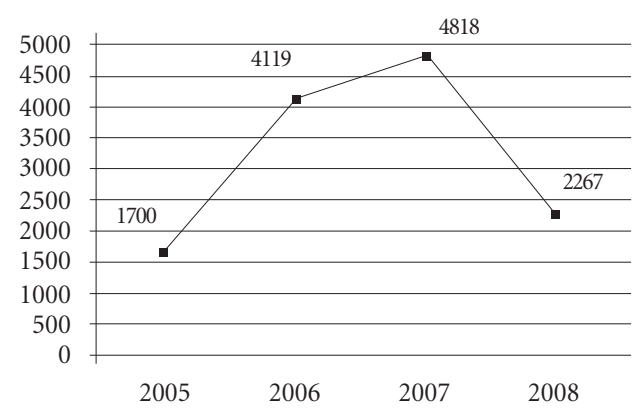

Gráfico 1. Gráfico evolutivo do total de doses de vacinas aplicadas na sala de vacinas NUST. balhadores viajantes. As vacinas contra influen$z a$ e tríplice viral tiveram decréscimo no número de doses aplicadas no ano de 2008, após as campanhas maciças em 2007, por estarem direcionadas a um recorte por faixa etária nas populações estritas da Fiocruz/Manguinhos. O Gráfico 2 reflete a redução da intervenção do tipo campanha e educação em saúde nas unidades Fiocruz, com valorização da sala de vacinação pelo NUST/CST, mas com baixa procura pelos trabalhadores.

Além da imunização em sala de vacina, foram implementadas campanhas planejadas pelo $\mathrm{Mi}$ nistério da Saúde para os anos de 2007 e 2008. Dentre estas, houve participação efetiva na Campanha Nacional de Imunização contra a Gripe, com vistas a reduzir a disseminação de gripes do tipo viral Haemofillus Influenzae em ambientes de trabalho. A especificidade dos ambientes fechados abrangia, assim, os trabalhadores das áreas administrativas e de serviços de saúde e laboratórios da Fiocruz/Manguinhos. As unidades atendidas foram: Ipec na faixa etária acima de 13 anos de idade, totalizando 309 nove doses; em

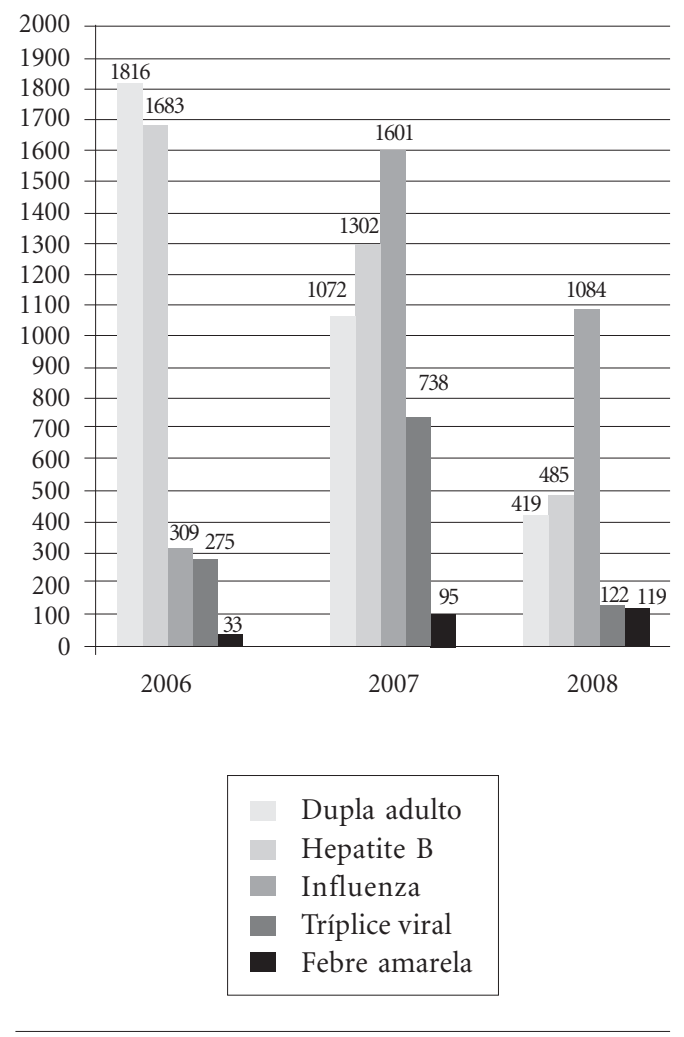

Gráfico 2. Gráfico evolutivo da cobertura vacinal da sala de vacina NUST - Calendário do Adulto e do Idoso. 
Farmanguinhos, na faixa etária de 13 a 64 anos, foram administradas 276 doses; no IFF realizaram-se atendimentos de 13 a 19 anos (três doses) e de 20 anos a 64 anos com 431 doses. Os adolescentes imunizados eram aprendizes e monitores dos convênios com escolas e instituições públicas de estudantes secundaristas da Escola Politécnica Joaquim Venâncio (EPJV). Em sala de imunização, foram aplicadas 729 doses da vacina.

A adesão à Campanha Nacional de Imunização contra a Rubéola, que teve como públicoalvo a faixa etária de 19 a 35 anos de idade para fins da erradicação da rubéola congênita, contou com a administração dos dois tipos de imunobiológicos disponibilizados: tríplice viral (sarampo, rubéola e caxumba) e dupla viral (rubéola e caxumba). Esta ação teve parceria com o CSEGSF visando atender a demanda dos trabalhadores de tal faixa etária no campus, e distribuiuse em: quatro doses na faixa etária de 12 a 14 anos, 118 doses na faixa etária de 15 a 19 anos da tríplice viral; 954 doses na faixa etária de 20 a 29 anos, 886 doses na faixa etária de 30 a 39 anos de dupla viral, totalizando, assim, 1.962 doses.

A imunização dentro do calendário ocupacional ${ }^{7}$ específica por processos de trabalho foi pontual e desenvolveu-se ao longo dos anos de implementação do programa. Algumas unidades apresentaram demandas direcionadas. Dentre estas, destacaram-se: a imunização antirrábica pré-exposição profilática à raiva humana para a unidade Cecal destinada aos trabalhadores nas atividades de tratadores de animais e veterinários, em conformidade com o centro de atenção à pré-exposição da SES/SMS; a imunização contra hepatite A na unidade IOC (laboratório de hantavirose) com trabalhadores cadastrados pelo programa no Centro de Referência em Imunobiológicos Especiais (CRIE - SES/RJ); a imunização contra a varicela, visando atender as unidades hospitalares que necessitaram bloquear surto de varicela nos setores de internação hospitalar do IFF e Ipec, direcionada a trabalhadores expostos a doenças infectoparasitárias em contato direto com pacientes com o diagnóstico de doença viral causada pelo vírus da varicela zoster, atendendo ao total de 13 trabalhadores.

\section{Conclusão e recomendações}

Esta experiência em imunização em saúde do trabalhador fundamentou-se nas políticas públicas de saúde, com enfoque na Política Nacional de Segurança e Saúde do Trabalhador (PNSST) e na vigilância em saúde do trabalhador, cuja lógica norteou-se pela implementação de programas de saúde, através da organização e gestão do cuidado em saúde, valendo-se das ferramentas de planejamento e gestão do SUS via rede de serviços de saúde, considerando-se as especificidades da organização do trabalho em saúde da instituição objeto desta ação.

Em relação aos princípios do campo da saúde do trabalhador e às concepções em saúde, trabalho e ambiente, primamos pelo envolvimento do coletivo de trabalhadores, levantamento das demandas e pelo planejamento da ação com cada unidade institucional pela interlocução com os representantes da gestão do trabalho, expandindo-a para a intersetorialidade e a interdisciplinaridade que se estabeleceram pelo envolvimento com as instâncias de gestão do SUS.

As exigências acerca do conhecimento técnico-científico em imunização trouxeram a necessidade de esforços para a promoção da saúde, por meio da comunicação e educação em saúde desenvolvida nos moldes de grupos operativos temáticos em imunização e biossegurança em nível local, com expansão coletiva pela inserção nas ações com caráter de planejamento regional do SUS diretiva para campanhas de imunização com integração junto à rede de serviços de saúde pelo PNI das unidades básicas de saúde da RA e da AP do território sanitário da ação local.

Antes de implementar atividades de imunização, é fundamental o conhecimento acerca da organização e gestão dos processos de trabalho em saúde para que se possa identificar os fatores de riscos biológicos imunopreveníveis. O ideal é desenvolver metodologias com as quais o trabalhador reflita acerca do seu próprio trabalho, pois isto facilitará o ato vacinal, devido à maturação no trabalhador das interfaces com a biossegurança e as estratégias defensivas que são elaboradas no conflito que permeia o adoecer no trabalho por doenças infectocontagiosas e transmissíveis devido à exposição ocupacional a bioagentes patogênicos.

A experiência em campanhas de imunização do trabalhador revelou-nos que o planejamento técnico da ação em saúde deve considerar a adesão por parte dos trabalhadores, com esclarecimentos que resultem no mínimo esforço e máximo alcance, com definição dos trabalhadores público-alvo e das vacinas específicas aos riscos biológicos imunopreveníveis. A divulgação das informações a serem sinalizadas requer ampla participação dos profissionais de recursos humanos das unidades e da instituição, devido às 
possibilidades de comunicação interna e coordenação dos fluxos de atendimentos por prioridades e quantitativos em relação às atividades e acessos aos postos de trabalho.

As palestras e os grupos operativos permitiram o fornecimento de informações técnicas sobre cada vacina, suas possíveis reações adversas/notificação e as condutas a serem adotadas pela epidemiologia e vigilância em saúde; promoveram a educação em saúde com orientações específicas e propiciaram a formação de multiplicadores.

Os grupos operativos minimizaram os impactos do processo de imunização, conferindo ao trabalhador conhecimentos sobre as reações em seu organismo, e asseguraram o seu retorno, permitindo o fechamento das doses subseqüentes, com finalização do esquema vacinal e estudo de soroconversão e níveis de titulação de anticorpos que tornam o trabalhador imune.

A adesão em relação à ação de imunização teve respostas pontuais. As atividades relacionadas ao funcionamento logístico da instituição, como jardinagem, manutenção, segurança, transporte, limpeza, almoxarifado e das atividades de produção de fármacos e vacinas, tiveram grande receptividade pelos trabalhadores, principalmente quando seguidas de ações de educação e promoção da saúde para o autocuidado, cabendo ressaltar que o maior quantitativo desses trabalhadores é terceirizado.

Entre os trabalhadores envolvidos em processos de trabalho com maior exposição aos fatores de riscos, como os profissionais de saúde, pesquisadores, alunos e bolsistas, a adesão foi satisfatória e representativa em unidades laboratoriais, devido ao envolvimento das equipes de gestão do trabalho, seguindo-se ações específicas do tipo sensibilização em biossegurança e mapeamento de riscos e campanhas e imunização nos postos de trabalho.

Para o público em geral, usuários e familiares dos trabalhadores, a adesão foi significativa durante as campanhas de imunização pela rede de serviços do SUS e estratégias do Ministério da Saúde e com ação conjunta desenvolvida em parceria com o Centro de Saúde Escola Germano Sinval Farias (CSEGSF) e com o Centro de Estudos em Saúde do Trabalhador e Ecologia Humana (CESTEH)/Ensp.

A atividade de imunização requer prévia relação dos riscos biológicos inerentes aos processos produtivos em saúde com os quais o trabalhador se expõe ao realizar as atividades/tarefas ao longo dos processos de trabalho em saúde, portanto ela deve estar articulada ao exame admis- sional por ser esta uma medida de prevenção e proteção à saúde preconizada para as instituições públicas ou privadas.

A relação de bioagentes patogênicos é uma informação a ser destacada para o Programa de Controle Médico e Saúde Ocupacional (PCMSO-NR-7) e o Programa de Prevenção de Risco Ambiental (PPRA-NR-9). O estudo criterioso dos riscos biológicos e das vacinas disponíveis no mercado também permitem o acompanhamento e o monitoramento de infecções geradas em atividades específicas que requerem a identificação prévia do agente infeccioso.

A imunoprevenção ocupacional envolve para o trabalho em saúde em laboratórios de saúde pública o controle da zoonose imunoprevenível do tipo raiva humana, pela vacinação preventiva dos envolvidos em processos de trabalho com animais, incluindo os trabalhadores médicos veterinários, tratadores de animais e pesquisadores que visitam cavernas e sítios arqueológicos suscetíveis a contraírem a raiva humana.

Profissionais de saúde capacitados em imunização pelas secretarias municipais de saúde assumem diretamente as responsabilidades técnicas de imunização e dos achados clínicos epidemiológicos da avaliação em saúde e biometria ocupacional. Cabe assim ao coordenador em saúde do trabalhador planejar, juntamente com a equipe multiprofissional, trabalhadores e representantes de recursos humanos da unidade, o estabelecimento de metas coletivas com definição de estratégias para o desempenho técnico científico dos programas de saúde em conformidade com as recomendações das câmaras técnicas do Ministério da Saúde.

Os indicadores oriundos dos exames ocupacionais serviram de base para informações esclarecedoras para a relação exposição, interação meio ambiente de trabalho e suscetível, patogênese com alteração, agravo e/ou lesão e fornecimento de nexos causais de possíveis adoecimentos no trabalho, ainda prevendo-se o contágio, a infecção e doenças ocupacionais transmissíveis.

As ações programáticas em saúde com caráter de prevenção e proteção requerem planejamento com integração sistêmica organizacional, demandando inter-relações subjetivas que envolvem a cultura organizacional e os processos de trabalho em saúde. Tal proposição exige replanejamento continuado com redefinições de cronogramas e contínua avaliação.

Esse empreendimento requer uma construção coletiva, que por sua vez se traduz em releituras e reavaliações posturais de liberalidade de ce- 
der poderes, criar e abrir espaços e fluir de acordo com as conjunturas e política institucional. $\mathrm{O}$ aprendizado é contínuo e seguido de amadurecimento organizacional no trabalho.

Ao longo dessa vivência, o fluxograma de atendimento do programa de imunização (Figura 1) demonstra novas experiências e contribui para elas. A Figura 2 sintetiza a ação de imunização e pode servir de aplicativo para outros programas de saúde pública no campo da saúde do trabalhador.

O planejamento e a operacionalização conforme os fluxogramas das figuras 1 e 2 interagem continuamente com a estrutura de informação no serviço de atenção ao trabalhador. Esta deve primar pela alocação dos dados que compõem a base epidemiológica de cobertura vacinal para a vigilância em saúde, permitindo-se assim acompanhar e avaliar a ação e a atenção em saúde do trabalhador.

Aspectos clínicos epidemiológicos como o monitoramento sorológico-técnico de grupos específicos de trabalhadores, alocação de recursos por prioridades e monitoramento do PCMSO ou da avaliação dos ambientes de trabalho, quando se tornam informação, podem gerar debates multidisciplinares e ação política de saúde do trabalhador.

A consolidação do sistema de informação em saúde do trabalhador e a construção dos fluxogramas de atendimento facilitam as práticas metodológicas de planejamento de saúde e permitem o traçar de estratégias para as reais especificidades das organizações em saúde, bem como promovem mudanças de paradigmas que ainda vinculam à imunização estritamente a intervenção higienista ocupacional.

O tema imunização em saúde do trabalhador está atrelado ao PCMSO, PPRA e ao calendário de imunização ocupacional. Entretanto, pode expandir-se e causar mudança organizacional pela vinculação ao pensamento dialético da comunicação, desenvolvido por Habermas ${ }^{26}$ ao que se denomina de "agir comunicativo" como um aplicativo do neoplanejamento empírico no setor de serviços em saúde - tendo como ferramenta a comunicação como conversação diante das demandas e conflitos durante o processo de condução da ação em saúde, pela contínua inte-

Planejamento
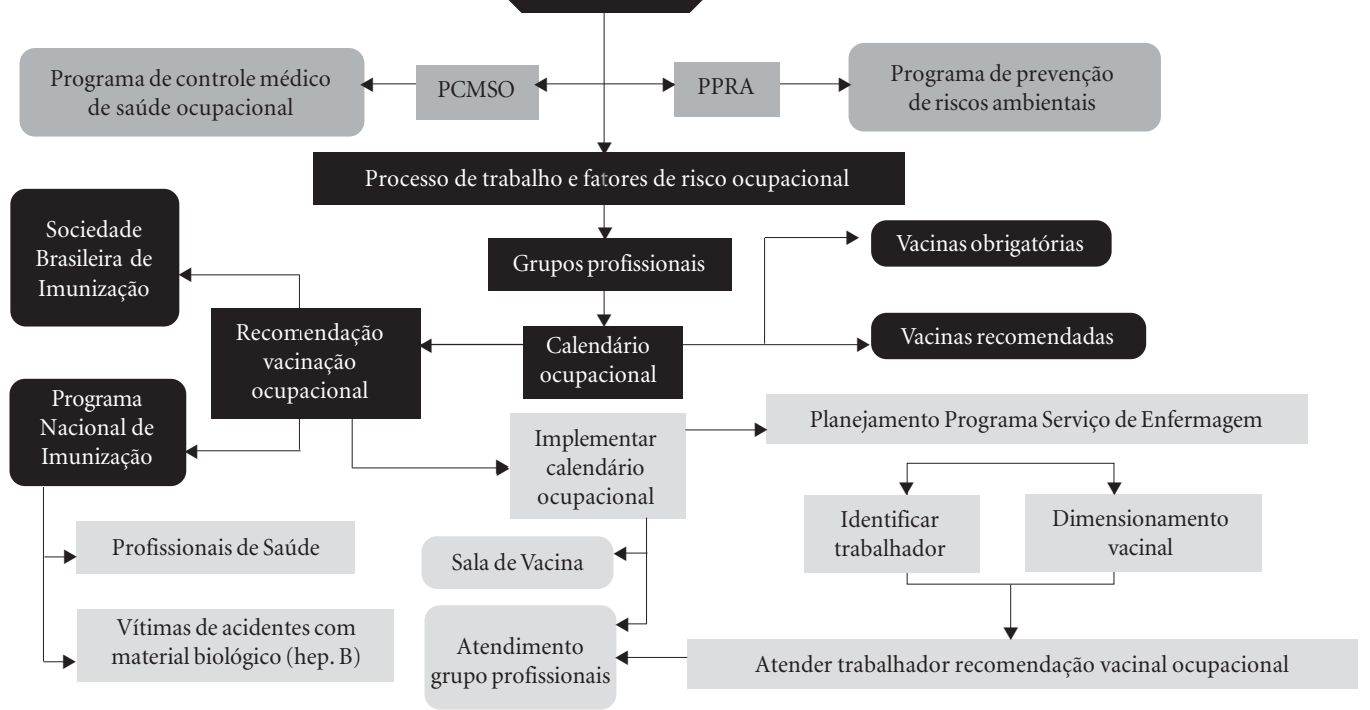

Início dos fluxogramas e/ou

processo de sensibilização

Atendimento das equipe

de Enfermagem e Medicina

Ações de Vigilância em

Saúde do Trabalhador

Figura 1. Fluxograma de atendimento ao Programa de Imunização Ocupacional. 

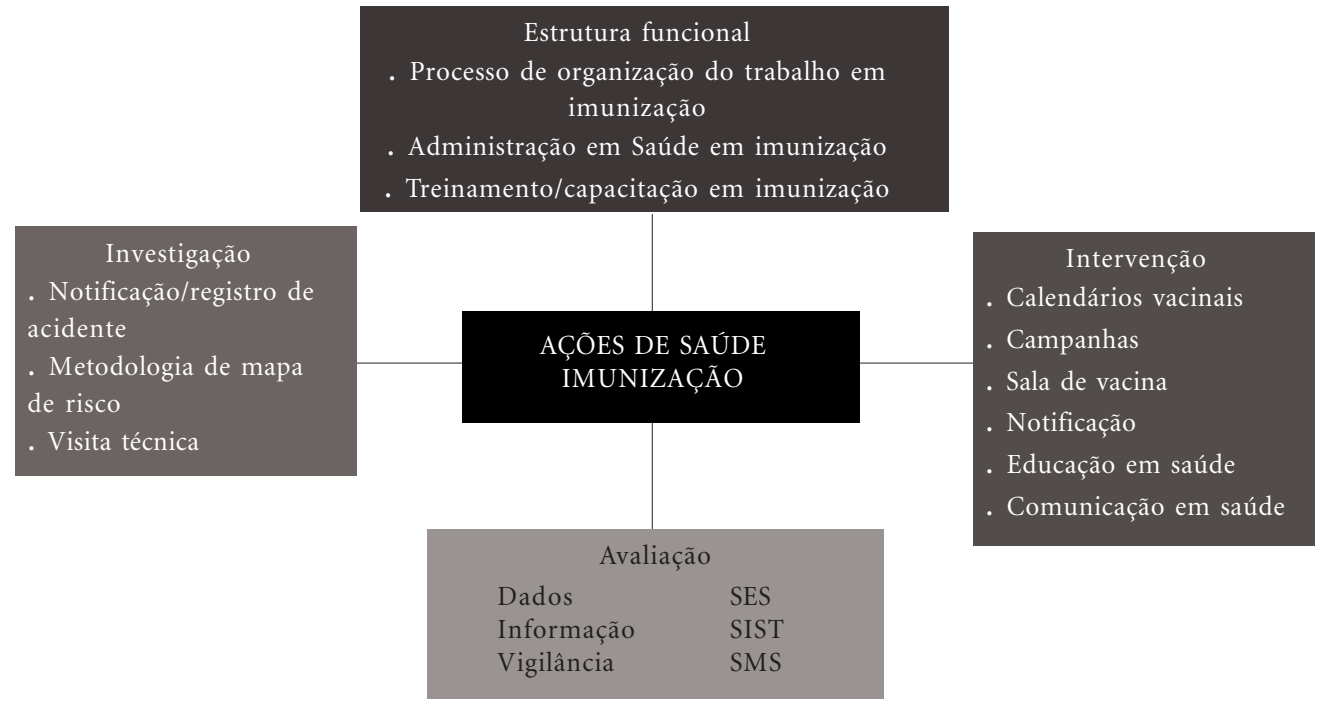

Figura 2. Quadro de metodologia de ações em Saúde do Trabalhador - Imunização

ração, que requer a aplicação de um projeto de atenção comum e sujeito às transversalidades do modelo de gestão por redes de serviços de saúde. Trata-se de um enfoque pertinente que poderá mesclar esta discussão e inseri-la na organização e nos processos de trabalhos em relação à insalubridade, periculosidade e perfil previdenciário profissional (PPP) com construção de uma política de atenuação, redução e eliminação de riscos biológicos e suas representações para o corpo, o indivíduo e o coletivo em relação a saúde, trabalho, ambiente, território e sociedade.

A imunização está inserida nas políticas públicas de saúde no Brasil, e sua articulação com ações preconizadas pelo sistema de saúde deve dar-se pelo território sanitário, que podem ser as APs e as RAs; logo, a instituição deverá seguir as normatizações técnicas preconizadas pelos órgãos competentes.

As campanhas do caso estudado e os atendimentos em sala de vacina funcionavam não só por agendamento e demanda espontânea, mas também em dependência do fornecimento das vacinas disponibilizadas pela rede básica de saúde, com o compromisso da universalidade e integralidade do SUS.

A organização do registro de dados, o acompanhamento e as informações do processo de vacinação deram-se pela ficha de arquivo cadas- tral do tipo espelho, anexando-se as cópias dos comprovantes ao prontuário do trabalhador, envio de estatística mensal para a RA e a AP do território sanitário de inserção da instituição e vinculação com a cobertura vacinal e os indicadores epidemiológicos do SUS, para alimentação do sistema de informação nacional em saúde, bem como em razão dos fatores de risco biológicos mapeados na instituição que também deve formular seus próprios indicadores e sistema local de informação em saúde do trabalhador.

Deve-se estabelecer parcerias técnicas e operacionais com o sistema de saúde e sua rede de cuidados e um formato de ação para a imunização em nível institucional, podendo-se empregar programas, campanhas e rotinas, que estarão em parceria com as proposições da rede de cuidados. Assim, as atividades previstas definiram aspectos técnico-científicos para as profissões em saúde e para o processo de planejamento e execução de uma agenda de serviço voltada para a atenção ao trabalhador, prevendo campanhas de vacinação nas unidades e o atendimento diário em imunização (sala de vacina).

As campanhas de imunização constituem uma intervenção eficaz para ações em espaços e ambientes de trabalho, permitindo o registro dos trabalhadores e dos processos de trabalho relacionados a bioagentes específicos e propiciando 
o fornecimento de subsídios e medidas específicas de segurança no trabalho.

Para a execução das ações do programa de imunização focadas na atenção à saúde do trabalhador, foram fundamentais a organização, a implantação e a manutenção da sala de imunização dentro do campus, eximindo a necessidade do encaminhamento a unidades de referência do SUS. A gestão de campanhas de imunização nos postos e unidades de trabalho também garantiu o sucesso do processo de imunização; já a sua redução comprometeu o processo do esquema vacinal. O levantamento realizado junto aos trabalhadores com a discussão do processo de trabalho permitiu a identificação de riscos e uma mobilização clara para a implantação de medidas que reduzam, minimizem e/ou extirpem os fatores geradores de doenças e agravos à saúde.

$O$ fomento de ações integradas entre ensino, pesquisa e extensão universitária, colaborando com a formação de recursos humanos técnicos e gerando conhecimento, permitiu ações em várias frentes de atividades.

A preceptoria e o desenvolvimento acadêmico profissional em imunização favoreceram a interação das áreas de conhecimento da enfermagem do trabalho, segurança do trabalho, imunização ocupacional e saúde do trabalhador, além de permitir um novo fazer em saúde e trabalho. Assim, ofereceram ao trabalhador e ao aluno espaços de configuração e colaboração em ensino-pesquisa e serviço para os campos da educação em saúde e da educação e formação de trabalhadores em saúde com o olhar para a saúde do trabalhador.

$\mathrm{O}$ articular da integração da equipe de trabalho em saúde do trabalhador prima pela interdisciplinaridade nas ações de vigilância em saúde, na integração metodológica e reconstrução em saúde coletiva, configurando-se como uma prática educativa de promoção da saúde, cujas bases centram-se no aprendizado mútuo e no inovar dos modos de se desenvolverem metodologias e teorias que se integrem ao SUS.

\section{Colaboradores}

PR Santos e NH Noronha foram responsáveis pela concepção, pelo delineamento e redação do artigo; UAO Mattos, pela redação e revisão crítica; D Silva, pela revisão crítica. 


\section{Referências}

1. Assunção AA. Uma contribuição ao debate sobre as relações saúde-trabalho. Cien Saude Colet 2003; 8(4):1005-1016.

2. Teixeira MG, Risi JB, Costa MCN. Vigilância epidemiológica. In: Roquayrol MZ, Almeida NF, organizadores. Epidemiologia e saúde. 6a ed. Rio de Janeiro: Medice; 2003. p. 313-345.

3. Brasil. Ministério da Saúde. Programa Nacional de Imunização (PNI). Brasília: Ministério da Saúde; 1973.

4. Brasil. Ministério da Saúde. Manual do Programa Nacional de Imunização. Brasília: Ministério da Saúde; 2002.

5. Minayo MSC, Machado JMH, Matos LBF, Oda LM, Monteiro TCN. Fiocruz saudável: uma experiência institucional. Cien Saude Colet 1998; 3(2):151-161.

6. Rouquayrol MZ, Façanha MC, Veras FMF. Aspectos epidemiológicos das doenças transmissíveis. In: Roquayrol MZ, Almeida NF, organizadores. Epidemiologia e saúde. $6^{\text {a }}$ ed. Rio de Janeiro: Medice; 2003. p. 229-286.

7. Ballalai I. Guia prático de vacinação em empresas. Rio de Janeiro: Sociedade Brasileira de Imunização-RJ; 2005.

8. Minayo-Gomez C, Thedim-Costa SMF. A construção do campo da saúde do trabalhador: percursos e dilemas. Cad Saude Publica 1997; 13(2):21-32.

9. Araújo GM, organizador. Normas regulamentadoras comentadas. 4a ed. Rio de Janeiro: GVC; 2003.

10. Brasil. Lei $\mathrm{n}^{\circ}$ 6.514, de 22 de dezembro de 1977. Altera o Capítulo V do Título II da Consolidação das Leis do Trabalho, relativo a segurança e medicina do trabalho, e dá outras providências. Diário Oficial da União 1977; 22 dez.

11. Brasil. Portaria $n^{\circ} 3.214$, de 8 de junho de 1978. Aprova as Normas Regulamentadoras - NR - do Capítulo V, Título II, da Consolidação das Leis do Trabalho, relativas a Segurança e Medicina do Trabalho. Diário Oficial da União (Supl.)1978; 6 jul.

12. Mastroeni MF. Introdução à biossegurança. In: Mastroeni MF, organizador. Biossegurança aplicada a laboratórios e serviços de saúde. 2a ed. São Paulo: Atheneu; 2005. p. 1-7.

13. Machado AA, Risi MRR. Aspectos psicológicos associados ao acidente ocupacional com material biológico potencialmente contaminado. In: Mastroeni MF, organizador. Biossegurança aplicada a laboratórios e serviços de saúde. 2a ed. São Paulo: Atheneu; 2005. p. 223-257.

14. Santos PR. Saúde do trabalhador no trabalho hospitalar: metodologias integradas de avaliação de experiências nos espaços de intervenção em hospitais no estado do Rio de Janeiro [tese]. Rio de Janeiro: Ensp/Fiocruz; 2009.

15. Santos PR. Projeto: Ações Integradas de Enfermagem em Vigilancia da Saúde do Trabalhador da Fiocruz. Rio de Janeiro: Fiocruz; 2006.
16. Santos PR, Henrique NN, Costa GAB, Conceição MT, Santos ME. Relatório do serviço de enfermagem em saúde do trabalhador Sest/Nust/CST/Direh. Rio de Janeiro: Fiocruz; 2006.

17. Santos PR, Henrique NN, Costa GAB, Conceição MT, Santos ME. Relatório do serviço de enfermagem em saúde do trabalhador Sest/Nust/CST/Direh. Rio de Janeiro: Fiocruz; 2007.

18. Santos PR, Henrique NN, Costa GAB, Conceição MT, Santos ME. Relatório do serviço de enfermagem em saúde do trabalhador Sest/Nust/CST/Direh. Rio de Janeiro: Fiocruz; 2008.

19. Hokerberg YH, Santos MAB, Passos SRL, Rozemberg B, Cotias PMT, Alves L, Mattos UAO. O processo de construção de mapas de risco em um hospital público. Cien Saude Colet 2006; 11(2):503-513.

20. Brasil. Ministério da Saúde. Fundação Nacional de Saúde (Funasa). Aspectos técnicos e administrativos da atividade de vacinação. Parte II. Brasília: Funasa; 2001. p. 65-292.

21. Aranda CMSS. Manual de procedimentos para vacinação. Parte I. Brasília: Ministério da Saúde/Fundação Nacional de Saúde; 2001. p. 17-45.

22. Brasil. Ministério da Saúde. Ação educativa nos serviços básicos de saúde. Brasília: Ministério da Saúde; 1981. (Série Educação em Saúde, no 2).

23. Brasil. Ministério da Saúde. Fundação Nacional de Saúde (Funasa). Coordenação de Imunização de Autossuficiência de Imunobiológicos. Manual de vigilância epidemiológica dos eventos adversos após vacinação. Brasília: Ministério da Saúde/Fundação Nacional de Saúde; 1998. p. 9-97.

24. Sato L. Replanejamento do trabalho como processo de construção e de negociação de significados. In: Borges LH, Moulin MGB, Araújo MD, organizadores. Organização do trabalho e saúde: múltiplas relações. Vitória: Edufes; 2001. p. 71-85.

25. Morgan G. Revelando a lógica de mudança: as organizações vistas como fluxo e transformação. In: Morgan G. Imagens da organização. São Paulo: Atlas; 1996. p. 239-278.

26. Habermas J. Teoría de la acción comunicativa. Madrid: Taurus; 1987.

Artigo apresentado em 18/4/2010

Aprovado em 8/10/2010

Versão final apresentada em 27/10/2010 